\title{
Increased T-regulatory cells within lymphocyte follicles in moderate COPD
}

\author{
J. Plumb*, L.J.C. Smyth*, H.R. Adams*, J. Vestbo*, , A. Bentley* and S.D. Singh*
}

\begin{abstract}
Lymphoid follicles in the lung parenchyma are a characteristic feature of chronic obstructive pulmonary disease (COPD). There are reports of altered CD4 T-regulatory cell numbers in COPD lungs, but the location of these cells within COPD lung tissue specific follicles has not been investigated.

The presence of $\mathrm{CD} 4^{+} \mathrm{FOXP3^{+ }}{ }^{\mathrm{T}}$-regulatory cells was assessed in surgically resected lung tissue from 12 COPD patients, 11 smokers with normal lung function and seven nonsmokers by combined immunofluorescence and immunohistochemistry.

Organised lymphoid follicles were observed in all three groups of patients, as well as lymphoid clusters lacking organisation. The percentage of CD4 cells that were T-regulatory cells were significantly increased $(p=0.02)$ within COPD $(16 \%)$ follicles compared with smokers $(10 \%)$ and nonsmokers $(8 \%)$. In contrast, there was no change $(p>0.05)$ in the percentage of T-regulatory cells in clusters or the subepithelium between groups.

Lymphoid follicles in COPD patients have increased T-regulatory cells. Therefore, T-regulatory activity may be altered within COPD Iymphoid follicles.
\end{abstract}

KEYWORDS: CD4 ${ }^{+}$OXP3 $^{+}$, follicles, smokers

hronic obstructive pulmonary disease (COPD) is characterised by progressive airway inflammation. Altered adaptive immunity is thought to play a role in the pathophysiology of this disease, as increased CD8 ${ }^{+} \mathrm{T}$-cells and B lymphocyte numbers are found in the airways of COPD patients compared with controls [1-3], with the number of these cells also increasing with disease severity $[1,4]$. It has been proposed that COPD has an autoimmune component $[5,6]$, but the antigenic stimulation responsible for lymphocyte activation is unclear. Possibilities include pathogens residing in the airways, such as viruses or bacteria, or smoking altering the presentation of self antigens including elastin [4, 6]. The regulation of pulmonary lymphocyte activity in COPD patients is not fully understood.

Regulatory T-cells are a subset of CD4 cells that inhibit activated lymphocytes through the release of suppressor molecules, such as interleukin (IL)10 and transforming growth factor (TGF)- $\beta$, or by cell-to-cell contact mechanisms $[7,8]$. FOXP3 is a member of the forkhead or winged helix family of transcription factors that is deemed essential for the development and function of T-regulatory cells $[9,10]$, and is considered the most specific available marker for T-regulatory cells [11, 12].

T-regulatory markers including FOXP3 have been used to show that smokers have increased numbers of T-regulatory cells in bronchoalveolar lavage fluid $[13,14]$ compared with nonsmokers. One of these studies also showed decreased Tregulatory numbers in COPD patients compared to smokers with normal lung function, suggesting decreased T-regulatory function in COPD. Tregulatory cell numbers have also been reported to be reduced in dispersed lung tissue lymphocytes from emphysema patients compared to controls, associated with reduced whole tissue FOXP3 mRNA levels and IL-10 production, further supporting the concept that T-regulatory function is reduced in COPD patients [6].

Lymphocytes that are attracted to tissue sites of inflammation can form organised structures known as tertiary lymphoid follicles. These have been reported in tissues such as the gut and joints $[15,16]$, and have also been observed within the lung parenchyma of COPD patients $[4,17]$. These follicles have a B-cell core with T-cells around the periphery [17]. Dendritic cells are also present in these follicles, suggesting that these structures are a site for chronic antigen presentation to lymphocytes [17]. It has been suggested that dendritic cells are involved in an aberrant immunological response within COPD follicles [18]. To our knowledge, T-regulatory cells in pulmonary lymphoid follicles in COPD patients have not been previously studied.
AFFILIATIONS

*University of Manchester, Education and Research Centre, South Manchester University Hospitals Trust, Manchester, UK, and ${ }^{*}$ Dept of Cardiology and Respiratory Medicine, Hyidovre Hospital, Hyidovre, Denmark.

CORRESPONDENCE J. Plumb

University of Manchester, Northwest Lung Centre

Wythenshawe Hospital Manchester M23 9LT UK E-mail: Jonathan.Plumb@ manchester.ac.uk

Received: July 032008 Accepted after revision: Jan 202009 First published online: Feb 052009 
We studied T-regulatory cell numbers within the lung parenchyma of patients with moderate COPD, focusing on lymphoid follicles. We hypothesised that parenchymal Tregulatory cell numbers would be altered in patients with COPD compared with normal control subjects. Using dual fluorescence immunocytochemistry we described the specific location of $\mathrm{CD}^{+} \mathrm{FOXP}^{+}$T-regulatory cells within the lung parenchyma of COPD patients.

\section{MATERIALS AND METHODS Study subjects}

In total, 30 patients undergoing surgical resection for suspected or confirmed lung cancer (table 1) were recruited. COPD was diagnosed based on a history of smoking for $\geqslant 10$ pack-yrs, typical symptoms (productive cough, breathlessness or wheeze) and airflow obstruction, defined as forced expiratory volume in $1 \mathrm{~s}$ (FEV1) $<80 \%$ predicted, and FEV1/ forced vital capacity $(\mathrm{FVC})$ ratio $<0.7$. These patients were all moderate COPD (Global Initiative for Chronic Obstructive Lung Disease (GOLD) stage 2). Non-COPD patients were categorised as either smokers or nonsmokers, which included ex-smokers with a pack-yr history of $\leqslant 1$ yr. All subjects gave written informed consent. The study was approved by the local research ethics committee (South Manchester Research Ethics Committee).

\section{Tissue sampling and processing}

Two tissue blocks were obtained from adjacent areas from the same lung, as far distal to the tumour as possible, then formalin fixed and paraffin embedded. For each patient, both tissue blocks were stained for immunohistochemical analysis. The primary antibodies used were as follows: CD3 (clone PS1, Novocastra, Newcastle Upon Tyne, UK), CD4 (clone IF6, Novocastra), CD8 (clone C8/144B, Dako, Glostrup, Germany), CD20 (L26, Vector Labs), CD62L (clone 9H6, Novocastra), and FOXP3 (Ab10563, Abcam, Cambridge, UK).

Lung tissues were cut into $4-\mu \mathrm{m}$ sections and lifted onto a polysine coated glass slide. Following heat induced epitope retrieval in Tris-EDTA buffer pH $8(10 \mathrm{mM}$ Tris Base, $1 \mathrm{mM}$ EDTA, $0.5 \%$ Tween 20) the lung sections were microwaved for $20 \mathrm{~min}$ at $800 \mathrm{~W}$. Primary antibody diluted in $1.5 \%$ normal serum (Vector Labs, Peterborough, UK) was applied overnight at $4{ }^{\circ} \mathrm{C}$. Endogenous peroxidase was quenched by incubating sections in $3 \% \mathrm{H}_{2} \mathrm{O}_{2}$ in methanol for $30 \mathrm{mins}$ at room

\begin{tabular}{lccc} 
TABLE 1 & Subject demographics & & \\
& COPD & Smokers & Nonsmokers \\
\hline Subjects & 12 & 11 & 7 \\
Age yrs & $67 \pm 6.9$ & $57 \pm 10.8$ & $64 \pm 15.2$ \\
Male/female & $8 / 4$ & $3 / 8$ & $2 / 5$ \\
Smoking history pack-yrs & $55(13-125)$ & $34.8(23-67)$ & 0 \\
FEV 1 \% predicted & $70.6 \pm 8.8$ & $82.8(13.1$ & $104(19$ \\
FEV1/FVC\% & $58.9 \pm 7.6$ & $75.7 \pm 6.3$ & NA \\
\hline
\end{tabular}

Data are presented as $n$, mean \pm SD or mean (range). COPD: chronic obstructive pulmonary disease; FEV1: forced expiratory volume in $1 \mathrm{~s}$; FVC: forced vital capacity; NA: not available. temperature. FOXP3 was detected using biotinylated goat anti-rabbit immunoglobulin (Ig)G secondary antibody (Vector Labs) in conjunction with an avidin-biotin peroxidase complex (Vector Labs) and diaminobenzidine substrate. Sections were counterstained with Meyer's haematoxylin (Sigma, Poole, UK). Omission of primary antibody from staining protocol and substitution of primary antibody with an isotype control antibody (Vector Labs) were used as negative controls.

\section{Combined immunofluorescence and immunohistochemistry}

Sections were pre-treated with Tris-EDTA buffer $\mathrm{pH} 8$ as described above, blocked with normal goat serum then incubated in either mouse anti-human CD4 (1:10; Novocastra) or mouse anti-human CD62L (1:50; Novocastra) overnight at $4^{\circ} \mathrm{C}$. Following detection using Alexa 568 conjugated goat anti-mouse IgG (1:200; Invitrogen, Paisley, UK) sections were washed and incubated in rabbit anti-human FOXP3 (1:800; Abcam) overnight at $4^{\circ} \mathrm{C}$ and detected as described. Sections were then incubated in $4^{\prime}, 6$-diamidino-2phenylindole (Invitrogen) to act as a fluorescent nuclear counterstain. Omission of one or other primary antibody, or both, was carried out on parallel sections to provide controls.

\section{Image analysis}

The number of $\mathrm{CD}^{+} \mathrm{FOXP}^{+}$T-regulatory cells was calculated within inflammatory follicles and clusters, and within the subepithelial layer of small airways; airways devoid of cartilage and glandular tissue and with an internal perimeter $<6 \mathrm{~mm}$. To obtain dual label images, bright field and fluorescent images from the same field were captured and digitally merged to determine the $\mathrm{CD}^{+} \mathrm{FOXP3}^{+}$cells. Digital micrographs were obtained using a Nikon Eclipse 80i microscope (Nikon UK Ltd, Surrey, UK) equipped with a QImaging digital camera (Media Cybernetics, Marlow UK) and ImagePro Plus 5.1 software (Media Cybernetics). Quantification of individual cell counts, follicle size and length of airway luminal perimeter was carried out using the ImagePro Plus 5.1 software. CD4 cells associated with the small airways were counted within an area of $100 \mu \mathrm{m}$ subepithelial. Cell counts were calculated and standardised to the number of positive cells $\cdot \mathrm{mm}^{-2}$ of the area of interest (cluster, follicle or subepithelia).

\section{Statistical analysis}

Data were not normally distributed, thus three-way comparisons between groups were performed using nonparametric ANOVA. Where significant differences were found by ANOVA, defined as $\mathrm{p}<0.05$, subsequent Mann-Whitney Utests were performed for two-way comparisons. Analysis was carried out using GraphPad InStat version 3.06 (GraphPad Software, Inc., San Diego, CA, USA).

\section{RESULTS}

\section{Distribution of tertiary lymphoid structures}

Tertiary lymphoid follicles were observed within samples from every patient group. Follicles were detected to be associated with the airway walls (fig. 1a) and also as isolated structures within the lung parenchyma (fig. 1b), as previously described $[4,17]$. These organised follicles were composed of a dense population of cells arranged in concentric layers (fig. 1c-f). The follicles had a large CD20 $0^{+}$B-cell core with an outer layer of 
$\mathrm{CD}^{+}$T-cells, comprising both $\mathrm{CD}^{+}$and $\mathrm{CD}^{+}$cells. Inflammatory clusters without an organised structure were also observed (fig. $1 \mathrm{~g}$ and $\mathrm{h}$ ). Within clusters, the T-cell population were no longer only associated to an outer layer but also distributed or scattered throughout. The majority of follicles $(89.4 \%$; 76 out of 85$)$ and clusters $(86.4 \%$; 38 out of 44$)$ were detected within the lung parenchyma, with the remainder associated with the airways (table 2).

In the 60 samples from the 30 subjects (i.e. COPD, smokers and nonsmokers combined) a numerical increase in number of
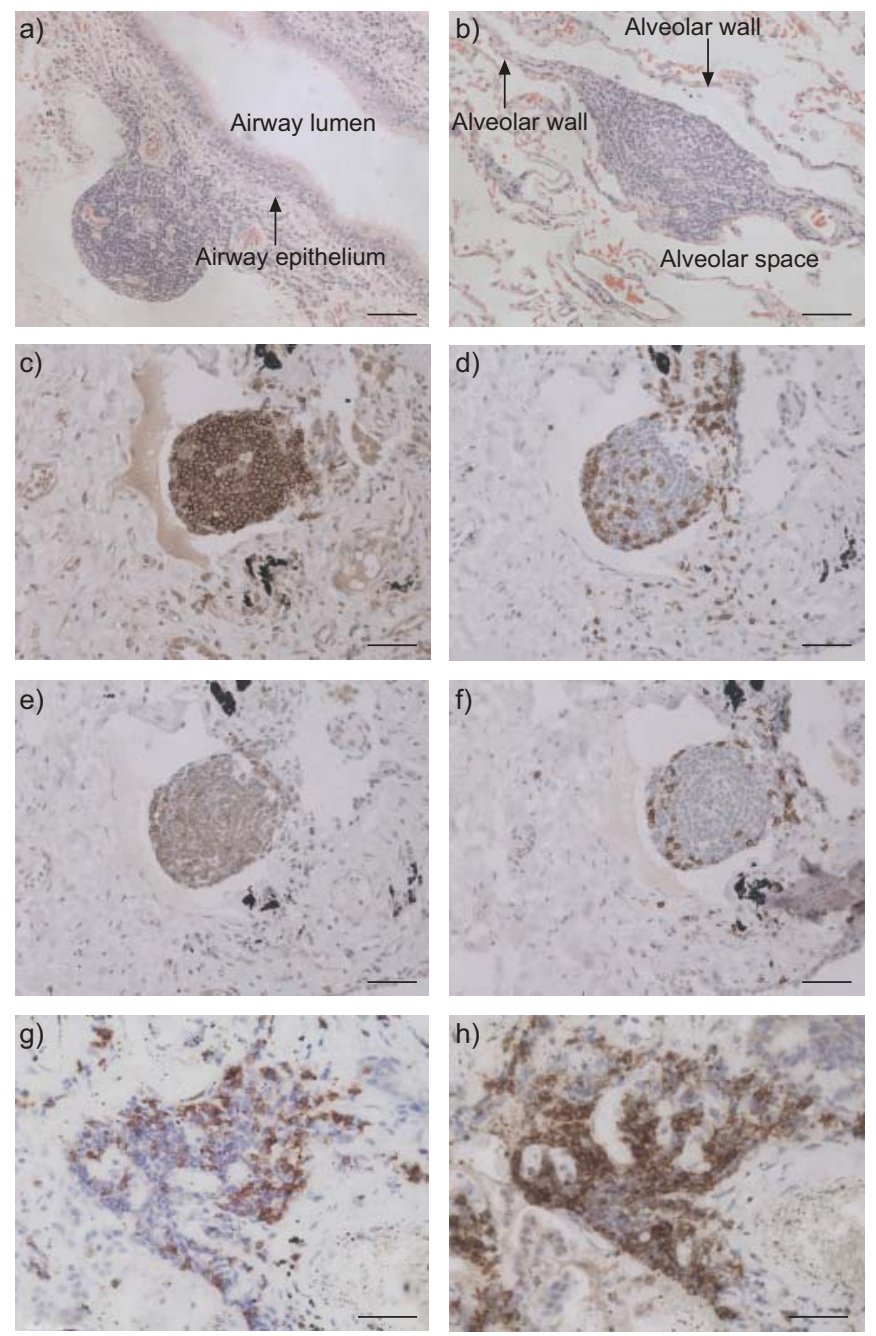

FIGURE 1. Representative images for the immunohistochemical analysis of the inflammatory cell components of tertiary lymphoid follicles and inflammatory clusters, within $4-\mu \mathrm{m}$ thick sections of human lung tissue. Immunohistochemical analysis was performed on serial sections to identify the presence of T-cells, B-cells and macrophages. a) Haematoxylin and eosin staining to illustrate a typical lymphoid follicle associated with a small airway and b) a parenchymal lymphoid follicle. c) 3,3'-diaminobenzidine detection (brown) of CD20 ${ }^{+}$B-cells (anti-CD20, clone L26) forming a central core. d) $C D 3^{+} T$-cells (anti-CD3, clone PS1), e) $C D 4^{+} T$ cells (anti-CD4, clone IF6) and f) CD8 ${ }^{+}$T-cells (anti-CD8, clone C8/144B) around the periphery of the follicle. Inflammatory clusters were observed that appeared to be less organised than follicles but were also composed of g) T-cells and h) B-cells. All sections were counterstained with Mayer's haematoxylin (blue). a-f) Scale bars $=50 \mu \mathrm{m} ; \mathrm{g}$ and $\mathrm{h}$ ) scale bars $=30 \mu \mathrm{m}$. follicles per sample was observed in COPD patients, with a trend towards significance $(p=0.068)$. There was no significant difference in the number of clusters between groups $(p=0.11)$.

\section{CD4 distribution}

ANOVA analysis showed a significant difference between COPD, smokers and nonsmokers in the number of $\mathrm{CD} 4^{+}$cells within follicles $(p=0.004)$. Mann-Whitney U-tests showed that the number of $\mathrm{CD}^{+}$cells were increased in COPD follicles (median 4,390 cells $\cdot \mathrm{mm}^{-2}$ ) compared with smokers (median 3,370 cells $\left.\cdot \mathrm{mm}^{-2} ; \mathrm{p}=0.0009\right)$. Although numerical differences were also observed between the numbers of $\mathrm{CD}^{+} \mathrm{T}$-cells within COPD and nonsmokers follicles, these were not statistically significant $(\mathrm{p}=0.1)$.

ANOVA analysis showed a significant difference between COPD, smokers and nonsmokers in the number of $\mathrm{CD} 4^{+}$cells in the subepithelia $(\mathrm{p}=0.02$; table 3$)$. Subsequent MannWhitney U-test analysis showed an increase in $\mathrm{CD}^{+} \mathrm{T}$-cells within COPD subepithelia (median $448 \mathrm{cells} \cdot \mathrm{mm}^{-2}$ ) compared with smokers (median 200 cells $\cdot \mathrm{mm}^{-2} ; \mathrm{p}=0.015$ ) and nonsmokers (median 260 cells $\cdot \mathrm{mm}^{-2} ; \mathrm{p}=0.04$ ), but no difference $(\mathrm{p}>0.05)$ between smokers and nonsmokers.

ANOVA analysis showed no difference between COPD, smokers and nonsmokers in the number of $\mathrm{CD}^{+}$cells in clusters.

\section{$\mathrm{CD4}^{+} \mathrm{FOXP3}^{+}$T-regulatory cells}

$\mathrm{CD}^{+} \mathrm{FOXP}^{+}$T-regulatory cells were predominantly observed around the periphery of inflammatory follicles (fig. 2a), whereas within clusters the T-regulatory cells were observed to be scattered throughout. The absolute number of $\mathrm{CD}^{+} \mathrm{FOXP3}^{+}$cells was lower in the subepithelial layer of small airways (fig. 2a-c and table 3). FOXP3 immunoreactivity was observed to be associated with cell nuclei. All FOXP3 ${ }^{+}$ cells identified were also $\mathrm{CD}^{+}$. $\mathrm{CD}^{+} \mathrm{FOXP3}^{+}$cells were not identified (fig. 2f). No immunoreaction product was observed when the FOXP3 primary antibody was omitted from the protocol, or substituted with an isotype control antibody, on adjacent serial sections (fig. $2 \mathrm{~g}$ and $\mathrm{h}$ ).

There were increased T-regulatory cell numbers in follicles of COPD patients compared with follicles in smokers and nonsmokers, whether expressed as total number or percentage of CD4 cells (table 3). Mann-Whitney U-tests showed that the

\begin{tabular}{|c|c|c|c|c|c|c|}
\hline \multirow[t]{3}{*}{ TABLE } & $\Xi 2$ & \multicolumn{5}{|c|}{$\begin{array}{l}\text { Distribution of inflammatory follicles and clusters } \\
\text { within lung tissue }\end{array}$} \\
\hline & \multicolumn{3}{|c|}{ Parenchymal } & \multicolumn{3}{|c|}{ Airway } \\
\hline & COPD $^{\#}$ & Smokers & $\begin{array}{l}\text { Non- } \\
\text { smokers }^{+}\end{array}$ & COPD $^{\#}$ & Smokers & $\begin{array}{l}\text { Non- } \\
\text { smokers }^{+}\end{array}$ \\
\hline Follicle & 39 & 28 & 9 & 6 & 1 & 2 \\
\hline Cluster & 18 & 9 & 21 & 0 & 0 & 6 \\
\hline \multicolumn{7}{|c|}{$\begin{array}{l}\text { Summary of the anatomical distribution of the inflammatory foci examined. } \\
\text { COPD: chronic obstructive pulmonary disease. }{ }^{\#}: 24 \text { tissue samples analysed; } \\
{ }_{:} 22 \text { tissue samples analysed; }{ }^{+}: 14 \text { tissue samples analysed. }\end{array}$} \\
\hline
\end{tabular}




\begin{tabular}{|c|c|c|c|c|}
\hline \multicolumn{5}{|l|}{$\mathrm{CD} 4^{+}$} \\
\hline Sub-epithelial & $448(160-1750)$ & $200(120-1260)$ & $260(50-940)$ & 0.02 \\
\hline Follicle & $4390(2040-10370)$ & $3370(1410-5640)$ & $2900(1740-7900)$ & 0.004 \\
\hline \multicolumn{5}{|l|}{$\mathrm{CD}^{+} \mathrm{Foxp}^{+}$} \\
\hline Sub-epithelial & $36(0-490)$ & $64(0-310)$ & $10(0-250)$ & NS \\
\hline Follicle & $570(100-1890)$ & $310(5-1280)$ & $350(0-860)$ & 0.0007 \\
\hline Cluster & $330(110-4350)$ & $560(110-5910)$ & $310(30-930)$ & NS \\
\hline \multicolumn{5}{|c|}{ Percentage T-regulatory cells } \\
\hline \multicolumn{5}{|c|}{$\mathrm{CD}^{+} \mathrm{Foxp}^{+}$} \\
\hline
\end{tabular}

Data is presented as median (range) for the absolute numbers of positive cells per unit area and as a percentage of the total CD4+ cells that were also Foxp3+. Within each group the absolute $\mathrm{CD} 4$ and $\mathrm{CD} 4^{+} \mathrm{Foxp} 3^{+}$populations were significantly different between areas of interest $(\mathrm{p}<0.0001)$. COPD: chronic obstructive pulmonary disease; NS: nonsignificant.

percentage of $\mathrm{CD}^{+} \mathrm{FOXP}^{+}$cells within follicles from $\mathrm{COPD}$ (median 160 cells $\cdot \mathrm{mm}^{-2}$ ) were significantly increased compared with smokers (median 100 cells $\cdot \mathrm{mm}^{-2} ; \mathrm{p}=0.032$ ) and nonsmokers (median 80 cells $\cdot \mathrm{mm}^{-2} ; \mathrm{p}=0.027$ ). There was no difference between smokers and nonsmokers follicles $(p=0.36)$.

There were no significant differences in T-regulatory cell numbers in clusters or the subepithelium between the groups, whether expressed as total number or percentage of CD4 cells (table 3).

In COPD patients, the percentage of the total CD4 population that were $\mathrm{FOXP3}^{+}$was significantly increased in the follicles compared with clusters or the subepithelium (table 3). In smokers and nonsmokers there were no differences in the percentage of the total CD4 population that were FOXP3 ${ }^{+}$ between the follicles, clusters and subepithelium (table 3).

\section{CD62L expression by T-regulatory cells}

To determine whether the $\mathrm{CD}^{+} \mathrm{FOXP}^{+}$T-regulatory cells express the secondary-lymphoid tissue-homing receptor CD62L, dual label expression of CD62L and FOXP3 was performed on one block per patient (fig. 2e). There were no significant differences between the percentage of $\mathrm{CD}_{2} \mathrm{~L}^{+} \mathrm{FOXP3}^{+}$cells between groups $(\mathrm{p}=0.68)$. The median (range) were $47(6-75) \%, 42(22-50) \%$ and $46(4-75) \%$ for COPD, smokers and nonsmokers, respectively.

\section{DISCUSSION}

This is the first study to quantify and describe the localisation of $\mathrm{CD}^{+} \mathrm{FOXP}^{+}$T-regulatory cells within human lung parenchyma of COPD patients. Previous studies have characterised T-regulatory cells from bronchoalveolar lavage fluid (BALF), dispersed lung cells and peripheral blood [6, 13, 14]. The major finding was that $\mathrm{CD}^{+} \mathrm{FOXP3}^{+}$T-regulatory cells were significantly increased within the inflammatory follicles from moderate COPD patients compared to smokers and nonsmokers with normal lung function.

We observed inflammatory lymphoid aggregates that appeared as unorganised structures (termed clusters) within COPD lung tissue. Similarly, loosely organised intestinal inflammatory clusters that may represent immature follicles have been described [19]. We hypothesise that the inflammatory clusters observed in our study may also reflect immature or early stage tertiary lymphoid follicles.

There was an increased proportion of T-regulatory cells within follicles of COPD patients compared to smokers and nonsmokers. However, in clusters and the subepithelia there was no difference in the proportion of T-regulatory cells between the groups. It has been hypothesised that dendritic cells within COPD follicles fail to induce appropriate T-cell responses but instead predominantly induce $\mathrm{CD}^{+} \mathrm{T}$-cell proliferation [18]. These CD8 cells exit the follicles and accumulate within the airways and parenchyma [18]. Therefore, the local immune microenvironment within COPD follicles appears to involve a variety of cell types, and our observation also suggests a role for T-regulatory cells within this microenvironment. We speculate that increased T-regulatory cell numbers are present in COPD follicles to suppress the interactions between dendritic cells and T-cells that lead to CD8 proliferation. This hypothesis should be studied further.

Recent studies have also described T-regulatory cells within the tertiary lymphoid follicles of patients with rheumatoid arthritis [15], and in mucosal biopsies of patients with inflammatory bowel disease [16]. As follicles have a B-cell core, it has been suggested that $\mathrm{FOXP3}^{+} \mathrm{T}$-regulatory cells can mediate B-cell activity directly [20]. We speculate that another possible role for T-regulatory cells in COPD lymphoid follicles is to suppress B-cell activation. 

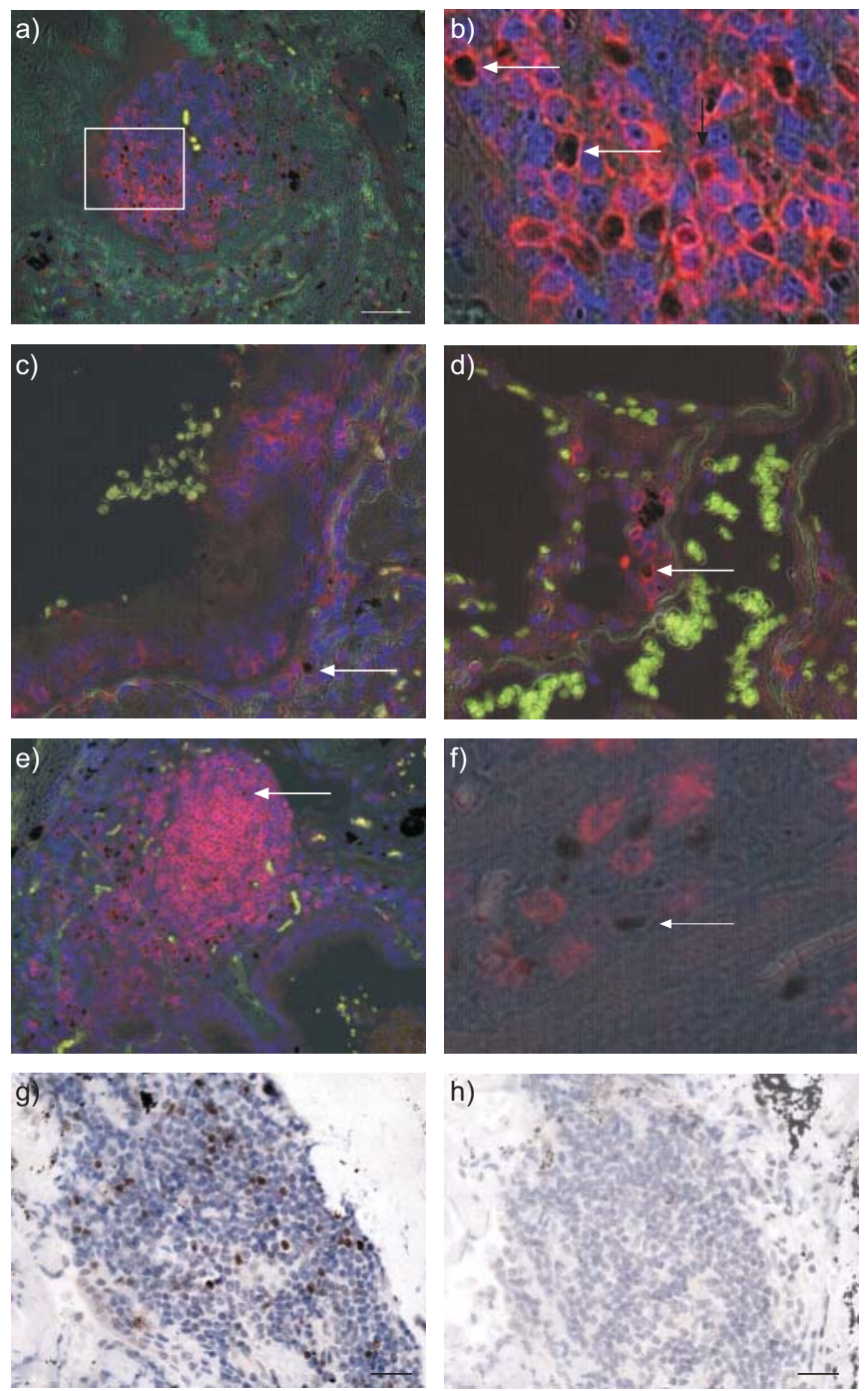

FIGURE 2. Representative images for the dual immunohistochemical and immunofluorescence detection of $\mathrm{CD}^{+} \mathrm{FOXP}^{+} \mathrm{T}$-regulatory cells within human lung tissue. Cell nuclei were counterstained with either a-f) 4',6-diamidino-2-phenylindole (blue stain) or $g$ and h) Mayer's haematoxylin (blue stain). a) CD4 ${ }^{+}$cells were identified using an Alexa-488 conjugated goat anti-mouse secondary antibody (red stain) and $\mathrm{FOXP3}^{+}$cells were detected using 3,3'-diaminobenzidine following indirect immunohistochemistry (brown stain). b) Increased magnification of the highlighted area in (a) demonstrating the distinct nuclear staining of FOXP3 (brown stain) in cells that are also $\mathrm{CD}^{+}$(red stain, indicated by arrow). c) A single $\mathrm{CD}^{+} \mathrm{FOXP3}^{+}$cell (arrow) detected within an airway submucosa. d) $\mathrm{A} \mathrm{CD} 4^{+} \mathrm{FOXP3}{ }^{+}$ cell detected within a population of $\mathrm{CD}^{+}{ }^{+} \mathrm{FOXP} 3^{-}$T-cells within an alveolar septum. e) A lymphoid follicle expressing an abundance of CD62L throughout with a few $\mathrm{CD62L}^{+} \mathrm{FOXP3}^{+}$cells (arrow). f) Sub-epithelial FOXP3 ${ }^{+}$cell (arrow) in close proximity to $\mathrm{CD}^{+} \mathrm{FOXP3}^{-}$cells (red stain). g) FOXP3 ${ }^{+}$cells detected in an inflammatory foci. h) Substituting anti-FOXP3 primary antibody for an isotype control antibody on an adjacent serial section resulted in no immunoreactivity being detected in the corresponding area. a) Scale bar $=50 \mu \mathrm{m} ; \mathrm{g}$ and h) scale bar $=25 \mu \mathrm{m}$. a, c, d and e) Green/yellow fluorescence is a result of the intrinsically fluorescent tissue components (elastic fibres and red blood cells). Autofluorescence is distinguished from positive fluorescence by forming a composite image of the red, green and blue channels. Autofluorescence is visible in all three channels and as a result appears as an amalgamation of the three colours, whereas the positive fluorescence is visible in only one channel and appears as the pure colour (red).
We investigated the numbers of T-regulatory cells within lung tissue, and further studies are needed to address the function of these cells, such as the expression of regulatory cytokines IL-10 and TGF- $\beta$. It has been reported that IL-10 production from lung tissue is reduced in COPD patients, suggestive of reduced T-regulatory activity [6]. Although we observed increased T-regulatory cells in COPD lymphoid follicles, whether their functional capacity is preserved is a key issue.

Previous studies have shown that smokers have increased numbers of T-regulatory cells compared with nonsmokers in BALF. There is evidence from one study, but not in a study performed by ourselves, that COPD patients have reduced Tregulatory cell numbers compared to smokers with normal lung function. In a different study using dispersed lung lymphocytes, the numbers of T-regulatory cells were decreased in emphysema patients compared to a mixed control group of smokers and nonsmokers. In contrast, our current observations suggest increased T-regulatory cell numbers in COPD patients. The differences between studies may be due to the fact that we specifically studied lymphoid follicles, in contrast to studies that have sampled the airway lumen by lavage. Cells within these distinct compartments may have different characteristics. Previous studies have used CD4CD25high expression by flow cytometry as the principal method for evaluating T-regulatory cell numbers. However, it is known that some CD4CD25high cells are activated rather than regulatory lymphocytes, and the best marker for regulatory T-cells is the one used in the current study, namely FOXP3.

FOXP3 $^{+}$T-regulatory cells have been categorised as being either secondary-lymphoid homing T-cells or nonlymphoid tissue homing $\mathrm{FOXP3}^{+} \mathrm{T}$-cells $[20,21]$. Differential expression of trafficking receptors, including CD62L, has been used to distinguish lymphoid homing T-regulatory cells [21]. The Tregulatory cells identified in follicles and clusters in the current study expressed CD62L, suggesting T-regulatory cell recruitment akin to that of secondary lymph nodes [21, 22]. The presence of COPD did not alter the expression of CD62L, indicating that the increased numbers of T-regulatory cells within COPD follicles was not due to over expression of this trafficking receptor.

Only $\sim 50 \%$ of the $\mathrm{FOXP3}^{+}$T-regulatory cells were $\mathrm{CD} 2 \mathrm{~L}^{+}$, possibly due to chemokine receptor switching that occurs on lymphocytes upon migration to lymphoid organs [21]. Antigen presentation within follicles may cause a secondary chemokine receptor switch enabling lymphocytes to migrate efficiently to nonlymphoid tissues [23]. Our findings of only $50 \%$ of regulatory T-cells expressing CD62L may be due to chemokine receptor switching.

The primary aim of this study was to analyse T-regulatory cell numbers within follicles. We also collected data on the number of follicles in samples from COPD patients and controls. We identified follicles associated with small airways as previously described [4, 17], as well as follicles within the lung parenchyma as previously described [17]. However, it was not our intention to further study differences in follicle numbers between groups, as this has been extensively reported elsewhere using larger sample sizes than the current study [4, 17]. Furthermore, we 
only included moderate COPD patients, while previous studies have included a greater range of patients to include severe (GOLD stage 3) and very severe (GOLD stage 4) patients. This is important as HoGG et al. [4] showed that there was a sharp increase in the number of follicles in severe and very severe COPD patients. Bearing in mind the limitation of the current study in terms of range of disease, it is clear that our study does not inform us about anything novel in terms of follicle prevalence. We would stress that we did not set out to investigate this.

Previous studies have shown an increase in follicle numbers in smokers compared with nonsmokers [24], but no difference between smokers and mild-to-moderate COPD [4, 25]. Our study showed an increase in T-regulatory cell numbers within follicles in moderate COPD compared with smokers. We speculate that this is an indicator of increased immunological activity within follicles of moderate COPD patients that contain antigen presenting dendritic cells, CD8 cells and large numbers of B-cells. It has been hypothesised that COPD has an autoimmune component $[5,6]$, and so increased T-regulatory activity in moderate COPD may be expected in an attempt to control autoimmunity. The progression from moderate-tosevere COPD, which is associated with a sharp increase in the number of follicles [4], may arise from a failure of regulatory mechanisms to suppress autoimmunity.

The subjects who participated in this study were undergoing investigations for suspected lung cancer. We cannot totally rule out any effects lung cancer may have had on our results. However, our observations that $>80 \%$ of tertiary lymphoid follicles were distributed within the lung parenchyma and not bronchus associated lymphoid tissue are in accordance with a recent study that used noncancerous lung tissue from lung reduction surgery and lung transplant patients [17].

In conclusion, we have observed increased proportions of Tregulatory cells within parenchymal follicles in moderate COPD patients. T-regulatory cells in normal conditions regulate ongoing immune responses and prevent autoimmunity. Altered function or numbers of these $\mathrm{T}$ regulatory cells are likely to be associated with changes in immune regulation. The exact role of T-regulatory cells within COPD lymphoid follicles requires further attention.

\section{STATEMENT OF INTEREST}

None declared.

\section{REFERENCES}

1 Saetta M, Baraldo S, Corbino L, et al. CD8+ve cells in the lungs of smokers with chronic obstructive pulmonary disease. Am J Respir Crit Care Med 1999; 160: 711-717.

2 Barnes PJ, Shapiro SD, Pauwels RA. Chronic obstructive pulmonary disease: molecular and cellular mechanisms. Eur Respir J 2003; 22: 672-688.

3 Gosman MM, Willemse BW, Jansen DF, et al. Increased number of B-cells in bronchial biopsies in COPD. Eur Respir J 2006; 27: 60-64.

4 Hogg JC, Chu F, Utokaparch S, et al. The nature of small-airway obstruction in chronic obstructive pulmonary disease. $N$ Eng J Med 2004; 350: 2645-2652.
5 Agusti A, MacNee W, Donaldson, Et al. : Hypothesis: does COPD have an autoimmune component? Thorax 2003; 58: 832-834.

6 Lee SH, Goswami S, Grudo A, et al. Antielastin autoimmunity in tobacco smoking-induced emphysema. Nat Med 2007; 13: 567-569.

7 Cederbom L, Hall H, Ivars F. CD $4^{+} \mathrm{CD} 25^{+}$regulatory T cells downregulate co-stimulatory molecules on antigen-presenting cells. Eur J Immunol 2000; 30: 1538-1543.

$8 \mathrm{Liu} \mathrm{H}, \mathrm{Hu} \mathrm{B}, \mathrm{Xu} \mathrm{D}$, et al. CD4+CD25+ regulatory T cells cure murine colitis: the role of IL-10, TGF-beta, and CTLA4. J Immunol 2003; 171: 5012-5017.

9 Hori S, Nomura T, Sakaguchi S. Control of regulatory T cell development by the transcription factor Foxp3. Science 2003; 299: 1057-1061.

10 Fontenot JD, Gavin MA, Rudensky AY. Foxp3 programs the development and function of $\mathrm{CD} 4+\mathrm{CD} 25+$ regulatory T cells. Nat Immunol 2003; 4: 330-336.

11 Fontenot JD, Jeffrey P, Rasmussen Williams LM, et al. Regulatory T cell lineage specification by the forkhead transcription factor Foxp3. Immunity 2005; 22: 329-341.

12 Roncador G, Brown PJ, Maestre L, et al. Analysis of FOXP3 protein expression in human CD4+CD25+ regulatory T cells at the singlecell level. Eur J Immunol 2005; 35: 1681-1691.

13 Smyth LJC, Starkey C, Vestbo J, et al. CD4 regulatory cells in COPD patients. Chest 2007; 132: 156-163.

14 Barceló B, Pons J, Ferrer JM, et al. Phenotypic characterisation of Tlymphocytes in COPD: abnormal CD4+CD25+ regulatory $\mathrm{T}$ lymphocyte response to tobacco smoking. Eur Respir J 2008; 31: 555-562.

15 Magalhães R, Stiehl P, Morawietz L, et al. Morphological and molecular pathology of the B cell response in synovitis of rheumatoid arthritis. Virchows Arch 2002; 441: 415-427.

16 Maul J, Loddenkemper C, Mundt P, et al. Peripheral and intestinal regulatory $\mathrm{CD} 4+\mathrm{CD} 25$ (high) $\mathrm{T}$ cells in inflammatory bowel disease. Gastroenterology 2005; 128: 1868-1878.

17 Van der Strate BW, Postma DS, Brandsma CA, et al. Cigarette smoke-induced emphysema: a role for the B cell? Am J Respir Crit Care Med 2006; 173: 751-758.

18 Tsoumakido M, Demedts IK, Brusselle GG, et al. Dendritic cells in chronic obstructive pulmonary disease: new players in an old game. Am J Respir Crit Care Med 2008; 177: 1180-1186.

19 Lorenz RG, Chaplin DD, McDonald KG, et al. Isolated lymphoid follicle formation is inducible and dependent upon lymphotoxinsufficient B lymphocytes, lymphotoxin $\beta$ receptor, and TNF receptor I function. J Immunol 2003; 170: 5475-5482.

20 Lim HW, Hillsamer P, Banham AH, et al. Cutting edge: direct suppression of B cells by CD4+CD25+ regulatory T cells. J Immunol 2005; 175: 4180-4183.

21 Lee JH, Kang SG, Kim CH. FoxP3+ T cells undergo conventional first switch to lymphoid tissue homing receptors in thymus but accelerated second switch to nonlymphoid tissue homing receptors in secondary lymphoid tissues. J Immunol 2007; 178: 301-311.

22 Venturi GM, Conway RM, Steeber DA, et al. CD25+CD4+ regulatory $\mathrm{T}$ cell migration requires $\mathrm{L}$-selectin expression: $\mathrm{L}$ selectin transcriptional regulation balances constitutive receptor turnover. J Immunol 2007; 178: 291-300.

$23 \mathrm{Lim} \mathrm{WH}$, Broxmeyer $\mathrm{HE}$, Kim $\mathrm{CH}$. Regulation of trafficking receptor expression in human forkhead box p3 regulatory T cells. J Immunol 2006; 177: 840-851.

24 Richmond I, Pritchard GE, Ashcroft T, et al. Bronchus associated lymphoid tissue (BALT) in human lung: its distribution in smokers and non-smokers. Thorax 1993; 48: 1130-1134.

25 Bosken $\mathrm{CH}$, Hards J, Gatter $\mathrm{K}$, et al. Characterization of the inflammatory reaction in the peripheral airways of cigarette smokers using immunocytochemistry. Am Rev Respir Dis 1992; 145: 911-917. 